\title{
Single Item Supplier Selection and Order Allocation Problem with a Quantity Discount and Transportation Costs
}

\section{Getachew Basa $^{1 *, 2}$, Till Becker ${ }^{1}$ and Abdelkader Kedir ${ }^{2}$}

${ }^{1}$ International Graduate School of Dynamics for Logistics, University of Bremen, Germany (*getachewb75@gmail.com).

${ }^{2}$ School of Mechanical and Industrial Engineering, EiT-M, Mekelle University, Ethiopia.

\begin{abstract}
In this paper, we address a single item supplier selection, economic lot-sizing, and order assignment problem under quantity discount environment and transportation costs. A mixedinteger nonlinear program (MINP) model is developed with minimization of cost as its objective, while lead-time, the capacity of the supplier and demand of the product are incorporated as constraints. The total cost considered includes annual inventory holding cost, ordering cost, transportation cost and purchase cost. An efficient and effective genetic algorithm (GA) with problem-specific operators is developed and used to solve the proposed MINP model. The model is illustrated through a numerical example and the results show that the GA can solve the model in less than a minute. Moreover, the results of the numerical illustration show that the item cost and transportation cost are the deciding factors in selecting suppliers and allocating orders.
\end{abstract}

Keywords: Supplier selection, Economic Order Quantity, Order allocation, Mixed-integer nonlinear programming.

\section{INTRODUCTION}

In today's competitive market, firms strive to reduce their costs and maximize their profitability through an integrated planning and control of their entire supply chain. One function of supply chain management that has a potential cost-saving advantage is purchasing since raw material and component parts constitute the major cost of the product in some cases up to $70 \%$ (Ghodsypour and Brien, 1998; Setak et al., 2012). The purchasing function determines the right supplier(s) with the right supply quantity at the right time not only to improve profitability through cost reduction but also to improve firm competitiveness. Purchasing also involves decisions regarding the optimal allocation of the order quantities to suppliers and the best transportation mode to use to satisfy the buyer's demand. Past researchers and industry practitioners solved the supplier selection, the order allocation and the carrier selection problem independently (Choudhary and Shankar, 2014; Mendoza \& Ventura, 2009). That is, three independent models will be developed so that the first model will select the suppliers and then the second model will determine the optimal allocation of order quantities among suppliers and finally the third model will select the transportation mode to transport the ordered items from the selected suppliers. However, this approach could sometime result in a suboptimal solution 
as it ignores the fact that the three decision making problems are interdependent on one another, and hence an optimal solution could be achieved by using an integrated modeling approach (Choudhary and Shankar, 2013; Liao and Rittscher, 2007; Mendoza and Ventura, 2009). In addition to the assignment of order quantities to suppliers, the supplier selection problem also needs to determine the optimal lot-sizing (economic order quantity, which is the amount of order at a time, when inventory costs are included in the cost function. However, only a few papers do consider the integrated decision of lot-sizing in the supplier selection decision (Pazhani et al., 2016). According to Ghodsypour and Brien (1998), there are two types of supplier selection problems, i) single sourcing, and ii) multiple sourcing suppliers selection problems. In the single sourcing, the supplier can satisfy the demand of the buyer in terms of quantity, delivery speed, and quality. Whereas, in the case of the multiple sourcing, no single supplier can fulfill the demand in terms of all the buyer's requirement. In this case, the buyer has to make a decision in selecting suppliers and allocate orders among them. In this paper, a single product is considered for procurement from multiple capacity-constrained suppliers with all-unit quantity discount offers. Since, the suppliers are located in different parts of the world, transportation cost for two (sea and air) alternative modes is also considered in the cost objective function. Once, the item arrives at a destination of one of the two alternative transportation modes, the item has to be transported to the main warehouse of the buyer using trucks. Hence, the model is made to include a transportation cost expression for using trucks in addition to the transportation mode selection cost function. The two modes of transportation are considered in the transportation cost modeling in spite of the obviously lower cost of sea transportation. But because the transportation cost from the ports to the warehouse and their impact on the speed of delivery in terms of lead-time are different. The cost function of the proposed model includes the inventory holding, ordering, transportation, and item costs. The lead-time, the capacity of supplier and truck capacity are considered as constraints. In order to solve the mixed-integer nonlinear program (MINLP) model proposed for solving the problem in this paper, an efficient genetic algorithm with problem-specific operator is constructed and used.

\subsection{Literature Review}

Supplier selection is a typical multi-objective or a multi-criteria decision problem, where cost, quality, delivery performance, and geographic location are the most commonly used criteria (Kahraman et al., 2003; Mendoza, 2007; Weber et al., 1991; Zhang \& Zhang, 2011). The supplier selection problem depending on the number of items to be procured, the number of suppliers used, and the planning period is categorized as a single or multiple items, single or 
multiple sourcing, and single or multiple planning periods respectively. The single type sourcing is commonly used when the supplier has sufficient capacity to satisfy the demand otherwise the demand is split among suppliers and hence the name multiple sourcing (Benton, 1991; Ghodsypour and Brien, 1998; Kilic, 2013; Razmi et al., 2009; Ustun and Demirtas, 2008). Finally, the supplier selection problem ( SSP) is also classified as a single-period problem where the problem is formulated for a single planning period (Ghodsypour and O'Brien, 2001; Narasimhan et al., 2006). When the order allocation is considered for multiple planning horizons it is called multiple period SSP (Demirtas and Üstün, 2008; Reza et al., 2008). The supplier selection and order allocation problem is complex when quantity discounts are considered instead of fixed prices for the items (Amid et al., 2009; Benton, 1991; Lee et al., 2013; Razmi and Maghool, 2010; Wang and Yang, 2009; Xia and Wu, 2007). Since, this paper is concerned with studies that integrate supplier selection, lot-sizing, order allocation, and transportation mode selection, the review concentrates on these specific studies which also include quantity discounts.

Hong et al. (2005) developed a mixed-integer linear program (MILP) with maximizing the revenue as an objective function while finding the optimal number of suppliers and meeting the demand of the customer. Liao and Rittscher (2007) proposed a multi-objective model for a single item capacitated multi-sourcing supplier selection, procurement lot sizing, and carrier selection problem with a dynamic demand under no quantity discount environment. Rajan et al. (2010) also developed a MILP for the multi-product multi-supplier supplier selection problem for an agricultural equipment retailer. Ghodsypour and O'Brien (2001) formulated the sourcing problem as mixed-integer non-linear programming to find the optimum number of suppliers and order quantity that minimizes the total cost of logistics. In their proposed model, the transportation cost is not explicitly modeled though it is mentioned. Karpak et al. (2001) proposed a goal programming formulation of the supplier evaluation and selection problem setting quality, cost, and delivery performance as the goals. The goal of their model is to find the right order quantity while meeting both demand and supply constraints. Narasimhan et al. (2006) formulated multi-objective programming using a minimum order size, maximum available supply, stipulated price, quality, and promised delivery-performance levels as criteria to evaluate the suppliers' performance. The authors recommended the use of and used analytical hierarchy process (AHP) to generate the relative weights of the five criteria. As it is the case with others, their model determines the optimal suppliers and the optimal order quantity. Wadhwa and Ravindran (2007) also developed a multi-objective formulation of the supplier evaluation and selection problem with the objective of minimizing price, lead-time, 
and rejection. They proposed three different solution approaches and compared the result of each approach to determine the best approach. The solution approaches used in their research were weighted objective, goal programming, and compromise programming method. Amid et al. (2009) proposed a fuzzy multi-objective model with three objectives: minimizing the net cost, minimizing the net rejected items and minimizing the net late deliveries with demand and capacity as constraints. The proposed model for the single item considers price breaks, but the net cost of the objective did not include the inventory holding, setup, and transportation costs. Mendoza and Ventura (2013), unlike the above papers, considered the question of when to order in addition to how much and from which supplier, by incorporating the inventory holding cost. They developed a mixed-integer nonlinear program to determine the order quantities with the objective of minimizing the sum of the item, inventory, and transportation costs while satisfying the capacity and demand constraints. Lee et al. (2013) proposed a mixed-integer program for the multi-period lot-sizing problem with quantity discounts under capacity and storage space constraint. The proposed objective is to minimize total cost which consists of ordering cost, holding cost, purchase cost and transportation cost. Choudhary and Shankar (2014) proposed a multi-objective integer linear program based on the minimization of net cost, percent of rejected items, and late deliveries to simultaneously determine the best suppliers, the supply quantity and the carrier to be used to transport the procured item for the capacitated SSP problem.

The literature review suggests that the case of single item, capacity-constrained multisourcing, supplier selection, and order allocation problem has been studied sufficiently. However, to the best of our knowledge the case with a quantity discount and intermodal freight cost has not been adequately addressed in the literature. This paper is aimed at developing a model that selects the best supplier(s), allocate order quantities to suppliers, and determine the economic lot size in such a way that it minimizes total cost while satisfying capacity, demand, and lead-time constraints.

\subsection{Problem Description and Model Development}

The procurement of a single item from multiple suppliers, which offer quantity discounts, is considered in the present case. The objective of the buyer is to split its annual demand of the items $(D)$ in to total order quantities among the suppliers $\left(d_{i}\right)$, determine the economic order quantity $\left(Q_{i}\right)$, and select the transportation mode to deliver the item into its warehouse with minimum total cost, while meeting capacity, demand and lead-time requirements. In the case of a decision to use foreign suppliers, procured items would be shipped either by air (Mode 1) or sea (Mode 2) transport. Once the item reaches at the port of the selected mode of 
transportation then it will be transported using trucks to the warehouse of the buyer. The model development stage starts by defining the objective function, in this case, the cost, which consists of the annual inventory holding, ordering, item, and transportation costs. The following notations are used in the model formulation.

\subsection{Notations (see Table 1)}

Table 1. Notations, descriptions and parameters.

\begin{tabular}{|c|c|c|}
\hline & Notation & Description \\
\hline \multirow{3}{*}{ Sets } & $\mathrm{i}$ & The set of suppliers \\
\hline & $\mathrm{k}$ & The set of price break points \\
\hline & $\mathrm{j}$ & The set of transportation alternative modes $\mathrm{j}=1,2$ \\
\hline \multirow{5}{*}{$\begin{array}{l}\text { Decision } \\
\text { Variables }\end{array}$} & $Q_{i}$ & Economic Ordered Quantity of the item from supplier i \\
\hline & $\mathrm{d}_{\mathrm{i}}$ & $\begin{array}{l}\text { The total amount of the item to be purchased from supplier } \\
\mathrm{d}_{\mathrm{i}} \in\left[\mathrm{d}_{\mathrm{i}, \mathrm{k}-1}, \mathrm{~d}_{\mathrm{ik}}\right] \text {, where } \mathrm{d}_{\mathrm{ik}} \text { is the maximum amount of supply } \\
\text { in the } \mathrm{k}^{\mathrm{th}} \text { discount interval }\end{array}$ \\
\hline & $\mathrm{X}_{\mathrm{i}}$ & $\begin{array}{l}\text { Is a binary variable, its value set equal to } 1 \text { if supplier i is use } \\
\text { and } 0 \text { otherwise }\end{array}$ \\
\hline & $\mathrm{Y}_{\mathrm{ik}}$ & $\begin{array}{l}\text { Is a binary variable, its value set equal to } 1 \text { if the orered quan } \\
\text { from supplier } \mathrm{i} \text { is in the } \mathrm{k}^{\text {th }} \text { interval, and } 0 \text { otherwise }\end{array}$ \\
\hline & $t_{i j}$ & $\begin{array}{l}\text { Is a binary variable, its value set equal to } 1 \text { if transportation } \\
\mathrm{j} \text { is used to transport from supplier } \mathrm{i} \text {, and } 0 \text { otherwise }\end{array}$ \\
\hline \multirow{14}{*}{ Parameters } & $\mathrm{C}_{\mathrm{i}}$ & $\begin{array}{l}\text { The unit cost of the item from supplier } \mathrm{i} \text {, where } \mathrm{C}_{\mathrm{i}} \text { is a functi } \\
\text {, i.e, } \\
\mathrm{C}_{\mathrm{ik}} \text { the unit cost of the item at the } \mathrm{k}^{\text {th }} \text { discount interval }\end{array}$ \\
\hline & $\mathrm{S}_{\mathrm{i}}$ & The ordering cost of the item from supplier i \\
\hline & $\mathrm{u}_{\mathrm{ij}}$ & $\begin{array}{l}\text { Unit transportation cost from supplier i using transportation } \\
\text { mode j }\end{array}$ \\
\hline & $F_{j}$ & $\begin{array}{l}\text { Frieght rate per full truck load per km from the intermodal } \\
\text { terminal of transportation mode } \mathrm{j} \text { to the warehouse of the } \\
\text { buyer }\end{array}$ \\
\hline & $\mathrm{B}_{\mathrm{j}}$ & $\begin{array}{l}\text { Distance between the destination point of } \\
\text { transportation mode } \mathrm{j} \text { to the warehouse of the buyer }\end{array}$ \\
\hline & $\mathrm{Cap}_{\mathrm{i}}$ & Capacity of supplier i \\
\hline & TCap & Truck load capacity \\
\hline & $\mathrm{n}_{\mathrm{i}}$ & Number of trucks per order required to transport $Q_{i}$ \\
\hline & $\mathrm{L}_{\mathrm{ij}}$ & $\begin{array}{l}\text { The lead time for acquiring the item from supplier i using } \\
\text { transportation mode } \mathrm{j}\end{array}$ \\
\hline & $\lambda_{\mathrm{i}}$ & Percent defective of supplier i \\
\hline & $\omega_{\mathrm{i}}$ & Score of supplier i, \\
\hline & $\mathrm{L}$ & $\begin{array}{l}\text { The maximum lead time the buyer allow for the item to be } \\
\text { Delivered. }\end{array}$ \\
\hline & $\mathrm{h}$ & The annual inventory holding cost rate \\
\hline & $\mathrm{D}$ & Demand for the item \\
\hline
\end{tabular}




\subsection{Minimize Cost}

The total cost considered include annual inventory holding cost, ordering cost, transportation cost, and the purchasing cost. The mathematical formulation of each cost component is as follows:

\subsection{Annual Inventory Holding Cost}

The annual inventory holding cost is obtained using eq. (1), where $\left(h C_{i k}\right)$ is the unit annual holding cost, and $\left(\frac{Q_{i} d_{i}}{2 D}\right)$ is the average inventory level during the planning period.

$$
\sum_{i=1}^{I} \frac{h C_{i} Q_{i} d_{i} X_{i}}{2 D}
$$

\subsection{Ordering Cost}

Equation (2) calculates the total ordering cost for the selected suppliers where $S_{i}$ is the ordering cost per order from supplieri, and $\left[\frac{d_{i}}{Q_{i}}\right]$ is the smallest integer greater than or equal to $\frac{d_{i}}{Q_{i}}$, which is the number of orders to be made over the planning period.

$$
\sum_{i=1}^{I} S_{i} X_{i}\left\lceil\frac{d_{i}}{Q_{i}}\right\rceil
$$

\subsection{Transportation Cost}

The transportation cost is the sum of the fixed and variable transportation costs and is obtained by eq. (3). The fixed transportation cost, which is the first term in eq. (3), is the cost of using trucks to transport items from the port of the selected mode of transportation to the warehouse of the buyer. While the variable transportation cost is the transportation cost of using either air or sea to transport the item. Where $u_{i j}$ and $\left(d_{i} x_{i} t_{i j}\right)$ are the unit variable transportation cost and the amount of the item transported from supplier $i$ using transportation mode $j$ respectively.

$$
\sum_{i=1}^{I} \sum_{j=1}^{J}\left(n_{i} B_{j} F_{j}\left\lceil\frac{d_{i}}{Q_{i}}\right\rceil+U_{i j} d_{i}\right) X_{i} t_{i j}
$$

\subsection{Purchase Cost}

The total purchasing cost is the sum of the product of the unit cost of the item and the total quantity supplied from each selected supplier.

$$
\sum_{i=1}^{I} C_{i} d_{i} X_{i}
$$


In the case of the all unit discount type, the cost of purchasing $d_{i}$ units from supplier $i$ can be expressed as:

$$
C_{i} d_{i}=C_{i k} d_{i}, \text { for } d_{i} \in\left[q_{i, k-1}, q_{i k}\right] \text {, and } k=1,2,3, \ldots, K, \forall i
$$

Since, $C_{i}$ is a function of $d_{i}$, the term $C_{i}$ in the objective function is nonlinear. To circumvent the nonlinearity, the following binary variable and constraints will be defined and added.

$$
\begin{aligned}
& Y_{i k}=\left\{\begin{array}{c}
1, \quad \text { for } d_{i} \in\left[q_{i, k-1}, q_{i k}\right] \text { and } k=1,2,3, \ldots, K \\
0, \quad \text { Otherwise }
\end{array}\right. \\
& C_{i} d_{i}=C_{i k} d_{i} Y_{i k} \quad, \forall i
\end{aligned}
$$

The following two constraints should be added to enforce that the ordered quantity falls within the valid quantity discount interval.

$$
\begin{aligned}
& q_{i, k-1} Y_{i k} \leq d_{i} \\
& d_{i} \leq q_{i k} Y_{i k}
\end{aligned}
$$

Hence, the expression for the cost objective function becomes:

Minimize:

$$
\begin{aligned}
Z_{1}=\sum_{i=1}^{I} \sum_{k=1}^{K} \frac{h C_{i k} Q_{i} d_{i} X_{i} Y_{i k}}{2 D}+\sum_{i=1}^{I} S_{i} X_{i}\left\lceil\frac{d_{i}}{Q_{i}}\right\rceil \\
+\sum_{i=1}^{I} \sum_{j=1}^{J}\left(n_{i} B_{j} F_{j}\left\lceil\frac{d_{i}}{Q_{i}}\right\rceil+U_{i j} d_{i}\right) X_{i} t_{i j}+\sum_{i=1}^{I} \sum_{k=1}^{K} C_{i k} d_{i} X_{i} Y_{i k}
\end{aligned}
$$

\subsection{Model Constraints}

\subsubsection{Demand}

The demand constraint states the sum total of the quantity ordered from each supplier should satisfy the demand of the customer.

$$
\sum_{i=1}^{I} d_{i} X_{i} \geq D
$$

\subsubsection{Supplier Capacity}

This constraint ensures that the total order to be made from each supplier should not exceed the periodic capacity of the supplier.

$$
d_{i} \leq C A P_{i}, \forall i
$$




\subsubsection{Lead-Time}

There are two ways of modeling the lead-time constraint. The first straightforward model for the lead-time constraint is that the lead-time of a supplier should always be less than the maximum lead-time imposed by the buyer $\left(l_{i} \leq L\right)$. However, this constraint will make the selection of suppliers which only meet this condition leaving other cost saving opportunities. In order to avoid the limitation of the first formulation of the lead-time constraint, we used the aggregate lead-time performance measure as proposed in Pan (1989). In the aggregate leadtime performance measure, since the longer lead-time of a supplier is compensated by a shorter lead-time, the modeler has a relative freedom of choosing a supplier which might not satisfy the lead-time constraint on its own but satisfy the requirement on the aggregate measure.

$$
\sum_{i=1}^{I} L_{i j} d_{i} t_{i j} \leq L D, \forall j \ldots
$$

\subsubsection{Transportation Mode and Truck Capacity}

Either of the transportation modes (sea or air) in the case of international suppliers should be selected. Once the item arrives at the destination of the selected mode of transportation, trucks will be used to transport the item to the company's warehouse, and hence the following constraints are added.

$$
\begin{array}{r}
\sum_{j=1}^{2} t_{i j}-X_{i} \geq 0, \forall i \\
Q_{i}-n_{i} * T C a p \leq 0 \\
X_{i}, Y_{i k}, \text { and } t_{i j} \in(0,1) \\
n_{i}, Q_{i}, d_{i} \in \text { Integer }
\end{array}
$$

and constraints (5) - (6).

\section{GENETIC ALGORITHM APPROACH}

Genetic algorithm (GA) is a search heuristic which is popular and widely used by researchers to solve various complex optimization problems. A GA mimics the natural selection process in nature to find near-optimal solutions to optimization problems by operating on potential solutions, which are called chromosomes. Each chromosome has a fitness value, which is a measure of how good a solution is to a particular problem. First, artificial chromosomes or a population of potential solutions are generated. Then a fitness base selection, crossover, and mutation operators will be applied to produce the new population called offspring. The 
following GA steps are utilized to find the best supplier and the corresponding optimal values of the decision variable.

\subsection{Step 1: Chromosome representation}

The chromosome representation (Table 2) for the problem in this paper is a 2-dimensional matrix where the column corresponding to the suppliers, the rows correspond to the decision variables. The economic order quantity and the order quantity are represented as positive integer value while the selection of supplier(s), mode of transportation are represented as binary integers. As shown in the mathematical model, the quantity of supply and the number of trucks are an integer multiple of the economic order quantity, and hence are functions of the EOQ. Therefore, the EOQ and the transportation mode selection variables are the sole decision variables required to be represented in the GA.

Table 2. Genetic representation of sample solution for a single item.

\begin{tabular}{|c|c|c|c|c|c|}
\hline & \multicolumn{5}{|c|}{ Suppliers } \\
\hline & 1 & 2 & 3 & 4 & 5 \\
\hline$\Xi \subseteq \overline{\mathrm{EOQ}}$ & 130 & 145 & 110 & 170 & 120 \\
\hline $\overrightarrow{\frac{2}{3}} \cdot \vec{s}$ Supplier selection & 1 & 0 & 1 & 0 & 1 \\
\hline 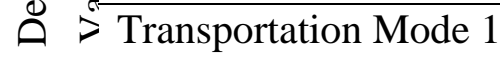 & 0 & 0 & 1 & 0 & 0 \\
\hline Transportation Mode 2 & 1 & 0 & 0 & 0 & 1 \\
\hline
\end{tabular}

\subsection{Step 2: Initial Population Generation}

In the population generation, a random initial solution is generated based on the maximum capacity of the supplier $[U B]$ and the minimum amount $[L B]$ a supplier is willing to supply, and hence the economic order quantity within $[L B, U B]$. The gene for the supplier selection and transportation mode selection is generated to have a binary value of 0 if the option is not selected 1 otherwise.

\subsection{Step 3: Fitness Value}

A fitness function is a function that returns a single value, which is supposed to reflect how good an individual chromosome is compared to a population. The higher the fitness value of an individual chromosome, the higher its probability of survival and reproduction in the next generation. The fitness function for each potential solution, in this case, is the minimum of the sum of the objective function and the constraint penalty function. For the model in this paper, demand and lead-time of delivery of the item are inequality constraints that are included as penalty functions in the fitness function as follows: 


$$
\text { fitness }=\text { objfun }+ \text { demand_penality }+ \text { leadtime_penalty }
$$

where, leadtime_penality $=$

$$
\begin{gathered}
2_{\text {num_gen }}^{\text {nu }}\left(\sum_{i=1}^{I} \sum_{j=1}^{J} l_{i p j} d_{i p} t_{i p j}-L_{p} D_{p}\right), \text { if } \sum_{i=1}^{I} \sum_{j=1}^{J} l_{i p j} d_{i p} t_{i p j}>L_{p} D_{p} \\
0, \text { otherwise } \\
\text { deman_penality }=2^{\text {num_gen }} *\left|\sum_{i=1}^{I} d_{i} X_{i}-D\right|
\end{gathered}
$$

Where, num_gen is the number of generations. The penalty will only be applied to late deliveries and hence the above inequality condition included.

\subsection{Step 4: Cross Over}

Cross over in GA is the process through which we simulate the recombination of chromosome strings that are cut at a randomly chosen points to produce two new offsprings. The two offsprings will inherit some part of their gene from each part (Beasley et al., 1993). To perform the cross over a standard vertical one-cut-point operator (Table 3) is applied for our ndimensional matrix with crossover probability of 0.85 .

\begin{tabular}{|c|c|c|c|c|c|c|}
\hline & & \multicolumn{5}{|c|}{ Suppliers } \\
\hline \multirow{5}{*}{ 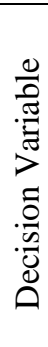 } & & 1 & 2 & 3 & 4 & 5 \\
\hline & EOQ & 130 & 145 & 110 & 170 & 120 \\
\hline & $\begin{array}{l}\text { Supplier } \\
\text { selection }\end{array}$ & 0 & 0 & 1 & 1 & 0 \\
\hline & Mode 1 & 0 & 1 & 0 & 0 & 0 \\
\hline & Mode 2 & 0 & 0 & 1 & 0 & 1 \\
\hline
\end{tabular}

Table 3. Example of the vertical one-cut-point crossover.

\section{A. Parent 1 solution}

\begin{tabular}{|c|c|c|c|c|c|c|}
\hline & & & & pplie & & \\
\hline & & 1 & 1 & 3 & 4 & 5 \\
\hline.$\stackrel{\Xi}{=}$ & EOQ & 85 & 60 & 260 & 40 & 190 \\
\hline$>$ & Supplier & 1 & 0 & 1 & 0 & 1 \\
\hline$\frac{\pi}{a}$ & Mode 1 & 1 & 0 & 0 & 0 & 0 \\
\hline ص & Mode 2 & 0 & 0 & 1 & 0 & 1 \\
\hline
\end{tabular}

\section{B. Parent 2 solution}

\begin{tabular}{|c|c|c|c|c|c|c|}
\hline & & \multicolumn{5}{|c|}{ Suppliers } \\
\hline \multirow{5}{*}{ 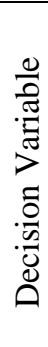 } & & 1 & 2 & 3 & 4 & 5 \\
\hline & EOQ & 130 & 145 & 110 & 40 & 190 \\
\hline & $\begin{array}{l}\text { Supplier } \\
\text { selection }\end{array}$ & 1 & 0 & 1 & 0 & 1 \\
\hline & Mode 1 & 0 & 1 & 0 & 0 & 0 \\
\hline & Mode 2 & 1 & 0 & 1 & 0 & 1 \\
\hline
\end{tabular}

\section{Offspring 1 solution}

D. Offspring 2 solution

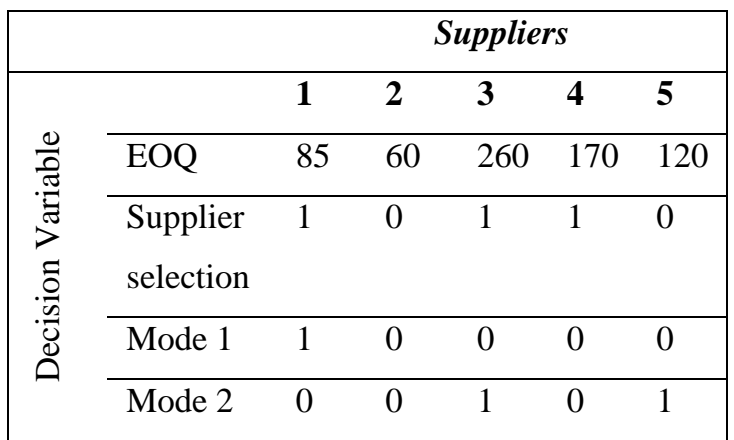




\subsection{Step 5: Mmutation}

The mutation process is applied to each individual child after cross over to change the value of a randomly selected gene. While the cross over enables the GA to quickly explore the solution search space, the mutation ensures that no points in the search space has a zero probability of being examined (Beasley et al., 1993). The mutation operator is applied to an offspring by altering the value of its gene (Table 4) randomly with a mutation probability of 0.01 . That is, a random number is first generated from a uniform $[0,1]$ distribution, and if the number generated is less than or equal to 0.01 , a randomly selected gene of the new offspring is mutated without violating the capacity constraint of the supplier.

\begin{tabular}{|c|c|c|c|c|c|c|}
\hline & & \multicolumn{5}{|c|}{ Suppliers } \\
\hline \multirow{5}{*}{ 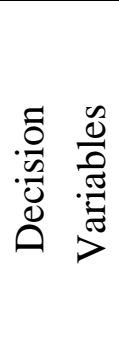 } & & A & B & $\mathrm{C}$ & D & $\mathrm{E}$ \\
\hline & EOQ & 130 & 145 & 110 & 205 & 190 \\
\hline & $\begin{array}{l}\text { Supplier } \\
\text { selection }\end{array}$ & 1 & 0 & 1 & 1 & 1 \\
\hline & Mode 1 & 0 & 1 & 0 & 0 & 0 \\
\hline & Mode 2 & 1 & 0 & 1 & 1 & 1 \\
\hline
\end{tabular}

Table 4. Gene selected for mutation.

\subsection{Step 6: Problem Specific Operators}

Like Liao \& Rittscher (2007) problem-specific operators are included to speed up the GA and at the same time to include the supply-demand equality constraint. However, unlike Liao \& Rittscher (2007) our problem-specific operator does not add or subtract the difference between demand and supply, to randomly selected suppliers. Instead of adding or subtracting the difference on a randomly selected supplier, our proposed problem-specific operator adds or subtracts the difference using an elitist selection approach as described below. The following steps describe how this problem specific operator is used to guarantee the demand constraint and speed up the search for a near-optimal solution.

1. Calculate the difference between the total supply and the demand for each item(supply. difference). And let smallest ${ }_{i}$ and largest $_{i}$ represent the $i^{\text {th }}$ smallest and largest supplied quantities respectively.

2. If supply. difference $>0$ :

If smallest $_{i} \geq$ supply. difference: smallest $_{i}=$ smallest $_{i}-$ supply. difference 
Else:

$$
\text { smallest }_{i}=0
$$

3. If supply. difference $<0$ :

$$
\begin{aligned}
& \text { If supply. difference }+ \text { largest }_{i}>\text { Capacity }_{i}: \\
& \text { largest }_{i}=\text { supply. difference }+ \text { largest }_{i}
\end{aligned}
$$

Else:

$$
\text { largest }_{i}=\text { Capacity }_{i}
$$

4. Repeat steps 1-3 until the difference between the supplied quantity and the demand for each item is zero.

\subsection{Step 7: Termination}

Repeat the processes of steps 3-6 until a defined stopping criterion is met. In this paper, the number of population generation is set to 200 and is used as the stopping criterion (Mitchell, 1996).

\section{AN ILLUSTRATION}

This section demonstrates the effectiveness of the proposed MINP model through an illustration. In this numerical illustration, nine suppliers are considered for selection and order allocation. The buyer's demand and lead-time requirements are 535 units and 2 months respectively. The unit price, price break offers, delivery lead-time, the capacity of suppliers are provided in table 5. The estimated order processing or management cost per order is 1000 Birr for local suppliers and 5000 Birr for foreign suppliers. The estimated fixed transportation cost per truck per $\mathrm{km}$ is 40 Birr for all distances greater than $100 \mathrm{~km}$ and 100 Birr otherwise. The distance between the seaports to the buyer's warehouse is $884 \mathrm{~km}$, and the distance from the airport to the warehouse is $50 \mathrm{~km}$. furthermore, all suppliers offer all unit quantity discounts with two discount intervals and the upper limit of the discount interval is also considered as the capacity of the supplier. In order to test the applicability of the proposed GA approach, the number of suppliers has been increased from one to nine with an increment of one supplier at each problem instance.

The proposed mathematical model and the proposed solution approach is coded in python 3.6.5 and the computational analysis was executed on a personal computer with a Core $^{\mathrm{TM}}$ i5-6200U @ $2.3 \mathrm{GHz}$, and $3.48 \mathrm{~GB}$ of RAM. As outlined in section 4 the GA's parameters has to be detrmined to find the optimal solution of any optimization problem. The GA parameters that has to be tuned are the crossover probability $\left(\mathrm{P}_{\mathrm{c}}\right)$, the mutation probability 
$\left(\mathrm{P}_{\mathrm{m}}\right)$, and the population size $(\mathrm{N})$. According to Srinivas \& Patnaik (1994), an experimental trial is the appropriate way to determine the optimal values of the GA parameters. Hence a $3^{3}$ factorial experiment is setup, and the program was run for 20 iterations. Table 2 presents the different values of the GA parameters used in testing the applicability and reliability of the proposed solution approach.

Table 5. Discount plan, transportation cost, and lead-time values.

\begin{tabular}{|c|c|c|c|c|c|c|}
\hline \multirow[t]{2}{*}{ Suppliers } & \multirow[t]{2}{*}{$\begin{array}{l}\text { Purchase } \\
\text { quantity }\end{array}$} & \multirow[t]{2}{*}{$\begin{array}{l}\text { Unit } \\
\text { cost }\end{array}$} & \multicolumn{2}{|c|}{$\begin{array}{l}\text { Transportation } \\
\text { cost }\end{array}$} & \multicolumn{2}{|c|}{$\begin{array}{l}\text { Lead-time* } \\
\text { (months) }\end{array}$} \\
\hline & & & Mode 1 & Mode 2 & Mode 1 & Mode 2 \\
\hline 1 & $\begin{array}{l}{[20,250]} \\
{[251,400]}\end{array}$ & $\begin{array}{l}344.9 \\
340.0\end{array}$ & 0 & 0 & 3.0 & 3 \\
\hline 2 & $\begin{array}{l}{[10,199]} \\
{[200,520]}\end{array}$ & $\begin{array}{l}423.2 \\
421.2 \\
\end{array}$ & 35.8 & 4.2 & 1.5 & 2.25 \\
\hline 3 & $\begin{array}{l}{[15,249]} \\
{[250,520]}\end{array}$ & $\begin{array}{l}627.1 \\
622.1 \\
\end{array}$ & 18.2 & 1.9 & 1.5 & 2.25 \\
\hline 4 & $\begin{array}{l}{[10,299]} \\
{[300,480]}\end{array}$ & $\begin{array}{l}419.5 \\
415.5 \\
\end{array}$ & 113.2 & 69.9 & 1.25 & 2.5 \\
\hline 5 & $\begin{array}{l}{[20,200]} \\
{[201,480]}\end{array}$ & $\begin{array}{l}302.1 \\
300.0\end{array}$ & 71.0 & 5.0 & 2.5 & 4 \\
\hline 6 & $\begin{array}{l}{[20,250]} \\
{[251,520]}\end{array}$ & $\begin{array}{l}812.8 \\
810.8\end{array}$ & 52.4 & 34.9 & 2.0 & 3 \\
\hline 7 & $\begin{array}{l}{[10,199]} \\
{[200,400]}\end{array}$ & $\begin{array}{l}489.4 \\
487.0 \\
\end{array}$ & 62.9 & 13.9 & 2.75 & 4 \\
\hline 8 & $\begin{array}{l}{[20,250]} \\
{[251,400]}\end{array}$ & $\begin{array}{l}518.4 \\
515.5\end{array}$ & 36.3 & 6.6 & 2 & 3 \\
\hline 9 & $\begin{array}{l}{[20,250]} \\
{[251,440]}\end{array}$ & $\begin{array}{l}465.5 \\
462.0\end{array}$ & 43.1 & $\mathrm{NA}$ & 2 & 3 \\
\hline
\end{tabular}

Note: *the lead-time includes the manufacturing and transportation time

Table 6. GA parameter values.

\begin{tabular}{|lcr|}
\hline $\boldsymbol{P}_{\boldsymbol{c}}$ & $\boldsymbol{P}_{\boldsymbol{m}}$ & $\boldsymbol{N}$ \\
\hline 0.75 & 0.01 & 100 \\
\hline 0.85 & 0.02 & 150 \\
\hline 0.95 & 0.03 & 200 \\
\hline
\end{tabular}

From table 6, 27 different combinations of GA parameter values are constructed and used to carry the experiment. Table 7 shows the GA parameter set and the minimum cost obtained for the particular GA parameter combination in use. 
Table 7. GA parameter sets and minimum cost value.

\begin{tabular}{|l|l|l|l|l|}
\hline S.No. & $\begin{array}{l}\text { GA Parameter sets } \\
\left(\boldsymbol{P}_{\boldsymbol{c}}, \boldsymbol{P}_{\boldsymbol{m}}, \boldsymbol{N}\right)\end{array}$ & $\begin{array}{l}\text { Minimum } \\
\text { cost }\end{array}$ & $\begin{array}{l}\text { Average } \\
\text { cost }\end{array}$ & Difference \\
\hline 1 & $(0.75,0.01,100)$ & $354,006.15$ & $363,411.86$ & $9,405.71$ \\
\hline 2 & $(0.75,0.02,100)$ & $354,006.14$ & $361,976.89$ & $7,970.75$ \\
\hline 3 & $(0.75,0.03,100)$ & $353,598.17$ & $362,605.00$ & $9,006.83$ \\
\hline 4 & $(0.75,0.01,150)$ & $353,598.17$ & $359,475.41$ & $5,877.24$ \\
\hline 5 & $(0.75,0.02,150)$ & $353,903.65$ & $359,157.81$ & $5,254.16$ \\
\hline 6 & $(0.75,0.03,150)$ & $353,801.49$ & $360,534.07$ & $6,732.58$ \\
\hline 7 & $(\mathbf{0 . 7 5 , 0 . 0 1 , 2 0 0 )}$ & $\mathbf{3 5 3 , 5 9 8 . 1 7}$ & $\mathbf{3 5 6 , 6 0 4 . 6 2}$ & $\mathbf{3 , 0 0 6 . 4 5}$ \\
\hline 8 & $(0.75,0.02,200)$ & $353,699.66$ & $356,745.61$ & $3,045.95$ \\
\hline 9 & $(0.75,0.03,200)$ & $353,801.49$ & $357,842.11$ & $4,040.62$ \\
\hline 10 & $(0.85,0.01,100)$ & $353,699.66$ & $367,340.92$ & $13,641.26$ \\
\hline 11 & $(0.85,0.02,100)$ & $355,599.94$ & $367,383.16$ & $11,783.22$ \\
\hline 12 & $(0.85,0.03,100)$ & $354,315.66$ & $369,590.49$ & $15,274.83$ \\
\hline 13 & $(0.85,0.01,150)$ & $354,212.15$ & $364,230.16$ & $10,018.01$ \\
\hline 14 & $(0.85,0.02,150)$ & $353,699.66$ & $359,535.16$ & $5,835.50$ \\
\hline 15 & $(0.85,0.03,150)$ & $353,699.66$ & $360,514.15$ & $6,814.49$ \\
\hline 16 & $(0.85,0.01,200)$ & $353,903.65$ & $357,920.40$ & $4,016.75$ \\
\hline 17 & $(0.85,0.02,200)$ & $353,598.17$ & $359,574.71$ & $5,976.54$ \\
\hline 18 & $(0.85,0.03,200)$ & $353,598.17$ & $359,995.34$ & $6,397.17$ \\
\hline 19 & $(0.95,0.01,100)$ & $355,476.51$ & $383,071.39$ & $27,594.88$ \\
\hline 20 & $(0.95,0.02,100)$ & $356,900.98$ & $394,443.81$ & $37,542.83$ \\
\hline 21 & $(0.95,0.03,100)$ & $356,126.88$ & $381,219.62$ & $25,092.74$ \\
\hline 22 & $(0.95,0.01,150)$ & $355,800.17$ & $370,205.81$ & $14,405.64$ \\
\hline 23 & $(0.95,0.02,150)$ & $353,598.17$ & $374,374.43$ & $20,776.26$ \\
\hline 24 & $(0.95,0.03,150)$ & $356,336.00$ & $371,422.27$ & $15,086.27$ \\
\hline 25 & $(0.95,0.01,200)$ & $355,584.06$ & $371,671.33$ & $16,087.27$ \\
\hline 26 & $(0.95,0.02,200)$ & $354,108.98$ & $372,163.15$ & $18,054.17$ \\
\hline 27 & $(0.95,0.03,200)$ & $355,688.67$ & $372,303.59$ & $16,614.92$ \\
\hline & & & & \\
\hline
\end{tabular}

In order to select the optimal combination of GA parameters, we select the GA parameter set that results in the minimum cost value and the minimum difference. The difference column is the difference between the average cost and the minimum cost. Hence, from table 7, the optimal GA parameters for our numerical example are $0.75,0.01$, and 200 for cross over rate, mutation rate, and population size respectively. Since no single supplier has the capacity to satisfy the demand of the buyer, at least two suppliers should be considered in the first case. That is, in the case of two suppliers, the buyer would select and allocate only to two suppliers from the nine potential suppliers. Hence, for this case, the best combination is to order 268 units from supplier 2 and 267 units from supplier 5. For the case of three suppliers, the result shows that 5,270, and 260 units of the item should be ordered from supplier 1, 2, and 
5. Table 8 shows the order quantities and the resulting minimum cost for each number of suppliers considered. Since the total order allocated to a supplier is the same as that of the economic order quantity, the table only provides the value for total order quantity. Furthermore, the selected mode of transportation for each option considered is mode 1. From Table 8 we observe that as the number of suppliers increased, the total cost also increases. The optimal number of suppliers for this particular numerical example is 2 .

Table 8. Results for a different number of suppliers.

\begin{tabular}{|llll|}
\hline $\begin{array}{l}\text { No. of } \\
\text { suppliers }\end{array}$ & Suppliers & Total order quantity & $\begin{array}{l}\text { Minimum } \\
\text { cost }\end{array}$ \\
\hline 1 & $\begin{array}{l}\text { No feasible } \\
\text { solution }\end{array}$ & & \\
\hline 2 & {$[2,5]$} & {$[268,267]$} & $\mathbf{3 5 3 , 5 9 8 . 1 7}$ \\
\hline 3 & {$[1,2,5]$} & {$[5,270,260]$} & $359,498.82$ \\
\hline 4 & {$[1,2,5,9]$} & {$[5,270,255,5]$} & $370,008.99$ \\
\hline 5 & {$[1,2,4,5,9]$} & {$[5,260,10,255,5]$} & $380,255.13$ \\
\hline 6 & {$[1,2,4,5,7,9]$} & {$[5,260,10,245,10,5]$} & $386,729.39$ \\
\hline 7 & {$[1,2,4,5,7,8,9]$} & {$[5,255,10,245,10,5,5]$} & $396,968.02$ \\
\hline 8 & {$[1,2,3,4,5,7,8,9]$} & {$[5,250,5,10,245,10,5,5]$} & $402,664.31$ \\
\hline 9 & {$[1,2,3,4,5,6,7,8,9]$} & {$[5,250,5,10,240,5,10,5,5]$} & $414,970.18$ \\
\hline
\end{tabular}

\section{CONCLUSION}

In this paper, we studied the economic lot-sizing, order allocation, and supplier selection problem under all-unit quantity discount and transportation costs. A mixed-integer nonlinear model is developed to make the decision of selecting the best supplier(s), determine the economic order quantity, the assignment of total orders, and which mode of transportation to use. The objective is to minimize the total cost, which includes the inventory holding cost, the ordering cost, the item cost, and transportation cost. The demand and lead-time requirements of the buyer have to be satisfied while not violating the capacity constraints of suppliers. Consideration of all parameters such as the capacity limitation of suppliers, quantity discount offers, intermodal transportation costs, and lead-time constraints make the supplier selection and order allocation problem more complicated but realistic. To solve the proposed model, a GA with a problem-specific parameter is proposed and tested on a numerical example, and the solution is obtained in 0.33 seconds. The results of the numerical illustration show that the item cost and transportation cost are the deciding factors in selecting suppliers and allocating order quantities. Moreover, as the minimum number of suppliers that are required to be used for procurement increases, the numerical illustration show that, the total cost increases. However, 
where there is no requirement on the number of suppliers to use, the model will determine the optimal order quantities and the suppliers. Since our proposed model is only applicable for a single item, future research could extend it to include the case of multiple items. Furthermore, since the model of this paper assumes a deterministic demand, considering the case of stochastic demand could also be a future direction. Another interesting extension to the problem could be the case of incremental quantitity discounts and business volume discounts, instead of the all-unit discount which is considered in this paper.

\section{ACKNOWLEDGEMENTS}

Authors sincerely thank the anonymous reviewer for their critical comments and suggestions which have significantly improved the quality of the paper.

\section{CONFLICT OF INTEREST}

There is no conflict of interests

\section{REFERENCE}

Amid, A., Ghodsypour, S. H \& O’Brien, C. 2009. A weighted additive fuzzy multiobjective model for the supplier selection problem under price breaks in a supply Chain. Int. J. Prod. Econ., 121(2): 323-332 (https://doi.org/10.1016/j.ijpe.2007.02.040).

Beasley, D., Bull, D. R \& Martin, R. R. 1993. An overview of genetic algorithms: Part 1, fundamentals. University Computing, 2(15): 1-16 (DOI:10.1017/CBO9781107415324.004).

Benton, W. C. 1991. Quantity discount decisions under conditions of multiple items, multiple suppliers and resource limitations. Int. J. Prod. Res., 29(10): 1953-1961 (https://doi.org/10.1080/00207549108948060).

Choudhary, D \& Shankar, R. 2013. Journal of Purchasing \{\&\} Supply Management Joint decision of procurement lot-size, supplier selection, and carrier selection. J. Purch. Supply Manag., 19(1): 16-26 (https://doi.org/10.1016/j.pursup.2012.08.002).

Choudhary, D \& Shankar, R. 2014. A goal programming model for joint decision making of inventory lot-size, supplier selection and carrier selection. Comput. Ind. Eng., 71(1): 19 (https://doi.org/10.1016/j.cie.2014.02.003).

Demirtas, E. A \& Üstün, Ö. 2008. An integrated multiobjective decision making process for supplier selection and order allocation. Omega, 36(1): 76-90. (https://doi.org/10.1016/j.omega.2005.11.003).

Ghodsypour, S. H \& Brien, C. O. 1998. A decision support system for supplier selection using 
an integrated analytic hierarchy process and linear programming. International Journal of Production Economics, 57: 199-212 (DOI:10.1016/S0925-5273(97)00009 -1).

Ghodsypour, S. H \& O’Brien, C. 2001. The total cost of logistics in supplier selection, under conditions of multiple sourcing, multiple criteria and capacity constraint. International J. Production Economics, 73(1): 15-27 (DOI:10.1016/S0925-5273(01)00093-7).

Hong, G. H., Park, S. C., Jang, D. S \& Rho, H. M. 2005. An effective supplier selection method for constructing a competitive supply-relationship. Expert Systems with Applications, 28(4): 629-639 (https://doi.org/10.1016/j.eswa.2004.12.020).

Kahraman, C., Cebeci, U \& Ulukan, Z. 2003. Multi-criteria supplier selection using fuzzy AHP. Logistics Information Management, 16(6): 382-394 (https://doi.org/10.1108/09576050310503367).

Karpak, Birsen., Kumcu, E \& Kasuganti, R. 2001. Purchasing materials in the supply chain: managing a multi-objective task. European Journal of Purchasing \& Supply Management, 7(3): 209-216 (DOI: 10.1016/S0969-7012(01)00002-8).

Kilic, H. S. 2013. An integrated approach for supplier selection in multi-item/multi-supplier environment. Applied Mathematical Modelling, 37(14-15): 7752-7763. (https://doi.org/10.1016/j.apm.2013.03.010).

Lee, A. H. I., Kang, H. Y., Lai, C. M \& Hong, W. Y. 2013. An integrated model for lot sizing with supplier selection and quantity discounts. Applied Mathematical Modelling, 37(7): 4733-4746 (https://doi.org/10.1016/j.apm.2012.09.056).

Liao, Z \& Rittscher, J. 2007. Integration of supplier selection, procurement lot sizing and carrier selection under dynamic demand conditions. International Journal of Production Economics, 107(2): 502-510 (https://doi.org/10.1016/j.ijpe.2006.10.003).

Mendoza, A. 2007. Effective methodologies for supplier selection and order quantity allocation. PhD dissertation, Department of Industrial Engineering, The Pennsylvania State University, University Park, PA.

Mendoza, A \& Ventura, J. A. 2009. Estimating freight rates in inventory replenishment and supplier selection decisions. Logistics Research, 1(3-4): 185-196 (https://doi.org/10.1007/s12159-009-0018-5).

Mendoza, A \& Ventura, J. A. 2013. Modeling actual transportation costs in supplier selection and order quantity allocation decisions. Operational Research, 13(1): 5-25. (https://doi.org/10.1007/s12351-011-0109-3).

Mitchell, M. 1996. An introduction to genetic algorithms. ISBN-13: 978-0262631853, MIT Press, Canbridge, MA, 205p. 
Narasimhan, R., Talluri, S \& Mahapatra, S. K. 2006. Multiproduct, multicriteria model for supplier selection with product life-cycle considerations. Decision Sciences, 37(4): 577-603 (https://doi.org/10.1111/j.1540-5414.2006.00139.x).

Pan, A. 1989. Allocation of order quantity among suppliers. Journal of Purchasing and Materials Management, 25(3): 36-39.

Pazhani, S., Ventura, J. A \& Mendoza, A. 2016. A serial inventory system with supplier selection and order quantity allocation considering transportation costs. Applied Mathematical Modelling, 40(1): 612-634 (https://doi.org/10.1016/j.apm.2015.06.008).

Rajan, A. J. 2010. Application of Integer Linear Programming Model for Vendor Selection in a Two Stage Supply Chain. Proceedings of the 2010 International Conference on Industrial Engineering and Operations Management Dhaka, 1-6.

Razmi, J \& Maghool, E. 2010. Multi-item supplier selection and lot-sizing planning under multiple price discounts using augmented ??-constraint and Tchebycheff method. International Journal of Advanced Manufacturing Technology, 49(1): 379-392 (https://doi.org/10.1007/s00170-009-2392-1).

Razmi, J., Rafiei, H \& Hashemi, M. 2009. Designing a decision support system to evaluate and select suppliers using fuzzy analytic network process. Computers and Industrial Engineering, 57(4): 1282-1290 (https://doi.org/10.1016/j.cie.2009.06.008).

Reza, M., Moghadam, S., Afsar, A \& Sohrabi, B. 2008. Inventory lot-sizing with supplier selection using hybrid intelligent algorithm. Applied Soft Computing, 8(4): 1523-1529 (https://doi.org/10.1016/j.asoc.2007.11.001).

Setak, M., Sharifi, S \& Alimohammadian, A. 2012. Supplier Selection and Order Allocation Models in Supply Chain Management : A Review. World Applied Sciences Journal, 18(1); 55-72 (https://doi.org/10.5829/idosi.wasj.2012.18.01.3258).

Srinivas, M \& Patnaik, L. M. 1994. Genetic Algorithms: A Survey. Computer, 27(6): 17-26 (https://doi.org/10.1109/2.294849).

Ustun, O \& Demirtas, E. A. 2008. An integrated multi-objective decision-making process for multi-period lot-sizing with supplier selection. Omega, 36(4): 509-521 (https://doi.org/10.1016/j.omega.2006.12.004).

Wadhwa, V \& Ravindran, A. R. 2007. Vendor selection in outsourcing, 34: 3725-3737 (https://doi.org/10.1016/j.cor.2006.01.009).

Wang, T. Y \& Yang, Y. H. 2009. A fuzzy model for supplier selection in quantity discount environments. Expert Systems with Applications, 36(10): 12179-12187 (https://doi.org/10.1016/j.eswa.2009.03.018). 
Weber, C. A., Current, J. R \& Benton, W. C. C. 1991. Vendor selection criteria and methods. European Journal of Opererational Research, 50(1): 2-18 (https://doi.org/10.1016/0377-2217(91)90033-R).

Xia, W \& Wu, Z. 2007. Supplier selection with multiple criteria in volume discount environments. Omega, 35(5): 494-504 (https://doi.org/10.1016/j.omega.2005.09.002).

Zhang, J \& Zhang, M. 2011. Supplier selection and purchase problem with fixed cost and constrained order quantities under stochastic demand. International Journal of Production Economics, 129(1): 1-7 (https://doi.org/10.1016/j.ijpe.2010.08.003). 